\title{
Tandem Photoredox Catalysis: Enabling Carbonylative Amidation of Aryl and Alkylhalides
}

\author{
José A. Forni ${ }^{[a] ¥}$, Nenad Micic ${ }^{[a] ¥}$, Timothy U. Connell[ ${ }^{[b]}$, Geethika Weragoda ${ }^{[c]}$ and Anastasios Polyzos ${ }^{\star[a],[c]}$ \\ [a] School of Chemistry, the University of Melbourne, Parkville, Victoria 3010, Australia. [b] School of Science, RMIT University, Melbourne, VIC 3000 , \\ Australia. ${ }^{[c]}$ CSIRO Manufacturing, Research Way, Clayton Victoria 3168, Australia.
}

\begin{abstract}
We report a new visible light-mediated carbonylative amidation of aryl, heteroaryl and alkyl halides. A tandem catalytic cycle of $\left[\operatorname{Ir}(\mathrm{ppy})_{2}(\mathrm{dtb}-\mathrm{bpy})\right]^{+}$generates a potent iridium photoreductant via a second catalytic cycle in the presence of DIPEA which productively engages aryl bromides, iodides and even chlorides as well as primary, secondary and tertiary alkyl iodides. The versatility of the in-situ generated catalyst is illustrated by compatibility with aliphatic and aromatic amines, high functional group tolerance and the late-stage amidation of complex natural products.
\end{abstract}

\section{Introduction}

Amide bond formation is fundamental to discoveries in the chemical and life sciences. The amide moiety is ubiquitous in natural and synthetic proteins and features prominently in versatile molecules including pharmaceuticals ${ }^{1}$ synthetic polymers, ${ }^{2}$ and agrochemicals. ${ }^{3}$ Owing to the importance of amides, traditional synthetic approaches to amide bond formation are being challenged. Modern synthetic methods typically employ stoichiometric coupling reagents to mediate the condensation of a carboxylic acid and amine (Figure $1 \mathrm{a}) .{ }^{4}$ These protocols liberate equivalents of toxic by-products and are generally incompatible with sterically congested amides. ${ }^{5}$ Given the prevalence of the amide functionality in pharmaceutical and agrochemicals, scaled processes are impeded by the expense associated with high molecular weight coupling reagents and the environmental impact of super-stoichiometric waste streams. ${ }^{6}$ With an increasing adoption of green chemistry principles by research and industrial laboratories, there in ongoing demand to develop a catalytic amide bond forming processes that are efficient, operationally simple, scalable and that reduce or eliminate the need for stoichiometric reagents. ${ }^{1 \mathrm{a}, 7}$

A key advance in catalytic amidation is the three-component coupling of an organohalide, carbon monoxide (CO) and amine (Figure 1a). ${ }^{8}$ Transition metal catalyzed carbonylative amidation readily generates aryl and vinyl amides by reductive dehalogenation of aryl and vinyl halides. The high energy barrier to oxidative addition resulting from metal catalyst deactivation with $\mathrm{CO}$ coordination ${ }^{9}$ imposes forcing conditions; high temperatures, extended reaction times and high $\mathrm{CO}$ pressure, which restricts application to activated substrates with sensitive functional groups. Furthermore, less activated alkyl halides are incompatible owing to competitive beta-hydride elimination. ${ }^{10}$

Advances in radical protocols have addressed the limitations of transition metal catalyzed amidation. ${ }^{11}$ Free-radical carbonylative amidation proceeds by the single electron reduction or photoinduced homolysis of a carbon-halide bond to furnish a carbon-centred radical that traps $\mathrm{CO}$ to generate amides via an acyl radical and amine. Despite the synthetic potential, the practicality of radical methods is impeded by hazardous reagents or high energy photochemistry. ${ }^{11}$ To overcome these limitations, photoredox strategies have avoided reagents and conditions that complicate traditional radical chemistry. ${ }^{12}$ However these are limited to alkyl substrates including alkyl iodides or alkyl organosilicates. ${ }^{12 a-c}$ Furthermore, the carbonylative amidation of aryl substrates with visible light photoredox catalysis remains unexplored. Consequently, a mild photocatalytic radical carbonylative amidation that engages aryl and alkyl substrates will solve an enduring challenge in synthetic chemistry (Figure 1b). 


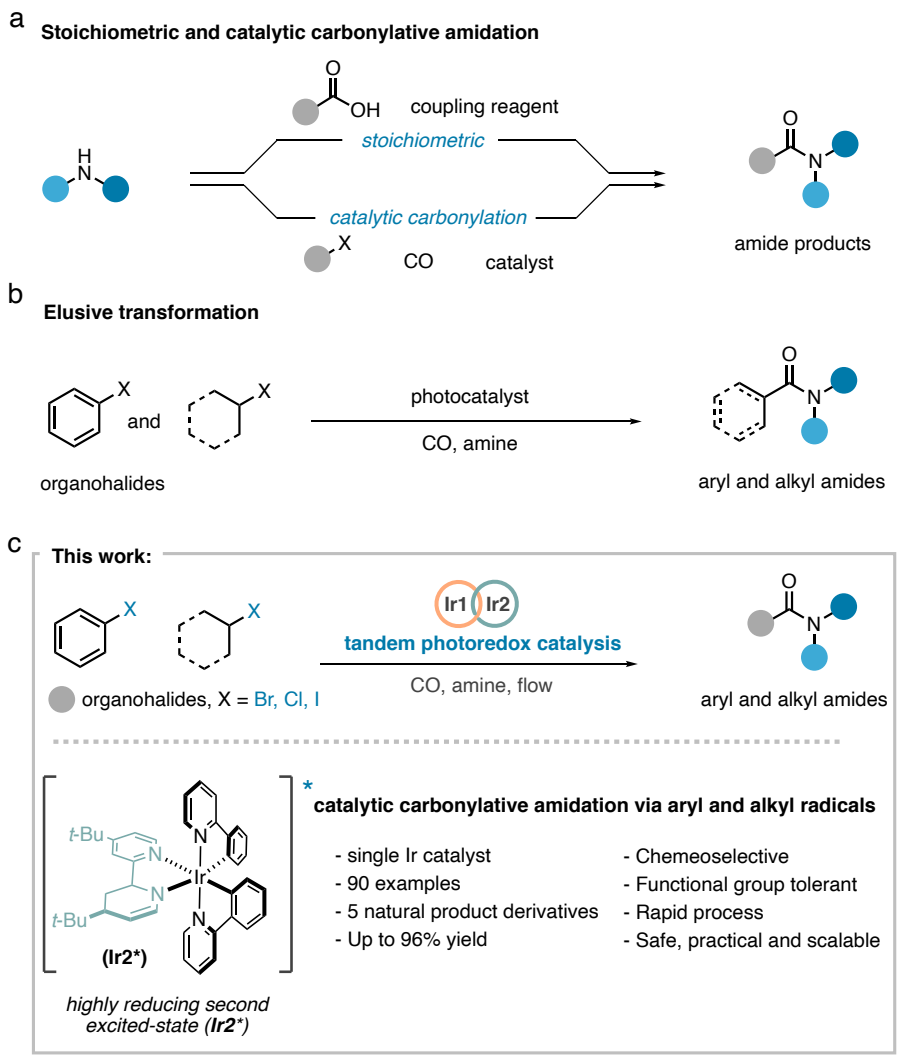

Figure 1. a) The classical generation of amide bonds via condensation reaction between a carboxylic acid, an amine and stoichiometric coupling agent (top) or a three-component transition metal catalyzed coupling of an organohalide, carbon monoxide (CO) and amine (bottom). b) A method for photocatalytic radical carbonylative amidation reaction of aryl and alkyl halides remains elusive. c) Our unified strategy for the carbonylative amidation of organohalides using tandem photoredox catalysis in continuous flow.

We endeavored to develop a unified method for the carbonylative amidation of aryl and unactivated alkyl halides with photoredox catalysis. In doing so, valuable amides could be generated from the diverse and commercially available organohalide building blocks under mild conditions, thus unlocking the full potential of catalytic radical amidation. The photoredox carbonylative amidation of aryl and alkyl halides, however, is challenged by availability of photocatalysts that promote the PET induced reduction of unactivated C$\left(s p^{2}\right)$ and $\mathrm{C}-\left(s p^{3}\right)$ halogen bonds. Multiphoton excitation catalysis has emerged as new strategy to overcome the thermodynamic limitations of visible light photoredox catalysis to generate high energy photoreductants. ${ }^{14}$ Recently our group disclosed a method for the in-situ generation of a second highly reducing iridium photocatalyst from $\left[\operatorname{lr}(\mathrm{ppy})_{2}(\mathrm{dtbpy})\right]^{+}$via a 2-photon tandem photoredox cycle ${ }^{15}$ (Figure 2a) and Nicewicz uncovered similar behaviour with organophotoredox catalysts. ${ }^{16}$ This strategy has been successfully applied to the reductive protodehalogenation of unactivated organohalides and showcases the ability common photoredox catalysts to yield a potent excited-state donors via multiphoton excitation.

Reported here is the first example of a general and practical strategy for the photoredox catalyzed carbonylative amidation of aryl, heteroaryl and alkyl halides. The platform harnesses dual strategy of visible-light tandem photoredox catalysis and continuous flow chemistry (Figure 1c). The tandem catalytic cycle of $\left[\operatorname{lr}(\mathrm{ppy})_{2}(\mathrm{dtb}-\mathrm{bpy})\right]^{+}$engages energy demanding aryl bromides, iodides and chlorides as well as primary, secondary and tertiary alkyl iodides via a multiphoton initiated secondary catalytic cycle. In combination with continuous flow processing, the strategy furnishes biologically relevant and diverse amides under mild reaction conditions with a broad substrate scope, atom economy, and scalability, offering a versatile reactivity mode for catalytic amide bond formation. 
a

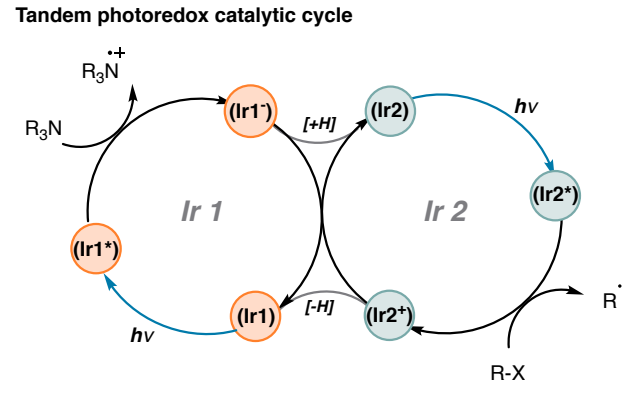

$\mathrm{R}-\mathrm{X}=\operatorname{aryl} \mathrm{Br}, \mathrm{Cl}, \mathrm{I} ;$ alkyliodides $\left(1^{\circ}, 2^{\circ}\right.$ and $\left.3^{\circ}\right)$ b

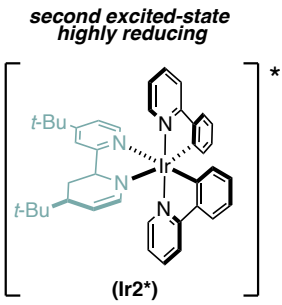

$E^{\circ}\left(\operatorname{Ir} 2^{+} / 1 \mathrm{r} 2^{*}\right)-3.0$ to $-1.70 \mathrm{~V}$

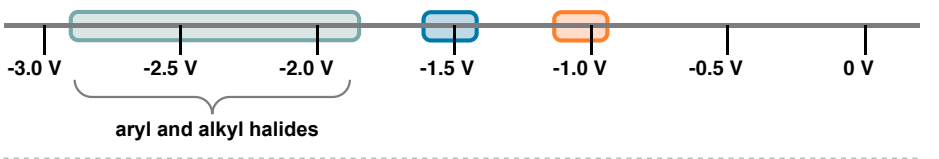

c
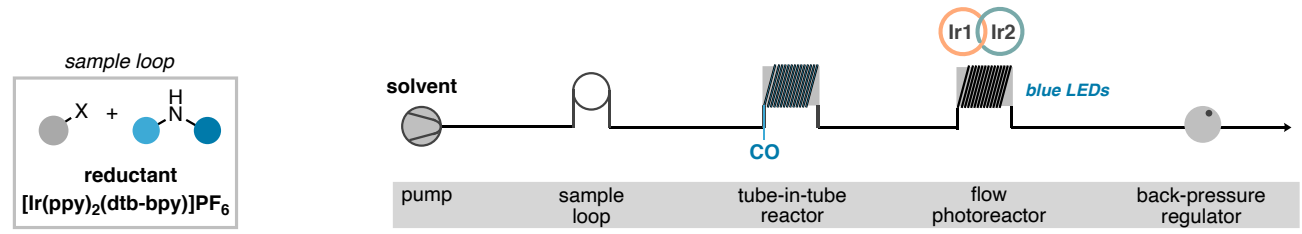

reduced photocatalyst

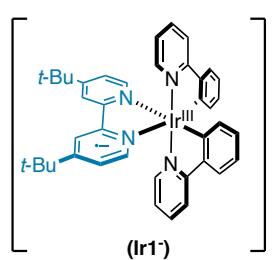

first excited-state

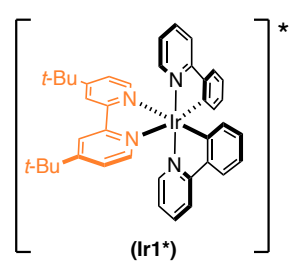

r1*)

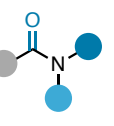

Figure 2. Design principle for the carbonylative amidation of aryl and alkyl halides. a) Tandem photoredox catalytic cycle of [Ir(ppy) 2 (dtb-bpy) $]^{+}$; b) The highly reducing second excited state (Ir2*); c) The flow chemistry platform.

\section{Results and Discussion}

The design plan for the carbonylative amidation of aryl and alkyl halides is shown in Figure 2. Central to this approach is the tandem photoredox cycle of $\left[\operatorname{lr}(\mathrm{ppy})_{2}(\mathrm{dtb}-\mathrm{bpy}) \mathrm{PF}_{6}\right.$ (Ir1) (Fig 2b). We envisioned that energy demanding organohalides could be engaged by the highly reducing second-excited $\left(\operatorname{Ir} 2^{*}\right)\left(\mathrm{E}^{\circ}\left(\operatorname{Ir} 2+/ \operatorname{Ir} 2^{*}\right)-1.70 \mathrm{~V}\right.$ to $\left.-3.0 \mathrm{~V}\right)$ to generate the corresponding $\mathrm{C}$-(sp $\left.{ }^{2}\right)$ and $\mathrm{C}$ $\left(\mathrm{sp}^{3}\right.$ )-centered radicals (Fig. 2c). Accordingly, the carbon-centered radical was proposed to react with excess CO to furnish the amide product. A key feature of the design plan is continuous flow chemistry. ${ }^{17}$ The flow chemistry platform (Supplementary Fig S2) incorporates a tube-in-tube gas/liquid reactor ${ }^{18}$ that permits the controlled and safe delivery of $\mathrm{CO}$ to the reaction solution ,13a,19 particularly at the partial pressures necessary to overcome the reversibility of the radical carbonylation step.

\section{Aminocarbonylation of Aryl and Heteroaryl Halides}

To initiate our study, we first examined the carbonylative amidation of methyl 4-iodobenzoate $(1)\left(E_{p}{ }^{\text {red }}=-1.78\right.$ vs SCE) as a representative substrate for the aryl halides (Table 1). We elected to use morpholine as the amine coupling partner with triethylamine (TEA) as sacrificial reductant and the catalyst $\left[\operatorname{Ir}(\mathrm{ppy})_{2}(\mathrm{dtb}-\mathrm{bpy})\right] \mathrm{PF}_{6}$ on the basis of previously established conditions for the reduction of aryl halides by the tandem photoredox system. ${ }^{15} \mathrm{~A}$ mixture of these reagents in acetonitrile was pumped through the gas-liquid reactor, enriched with $\mathrm{CO}$ at 25 bar, then irradiated inside the photoreactor with $54 \mathrm{~W}$ blue LEDs. The photoreactor residence time was initially set to $5 \mathrm{~min}$. The initial reaction conditions furnished the desired aminocarbonylation product $2 \mathrm{a}$ in $39 \%$ yield with incomplete consumption of the aryl halide (Table 1, entry 1 ). 
Table 1. Optimization and control experiments for the aminocarbonylation of aryl iodide 1 in flow ${ }^{\text {a }}$

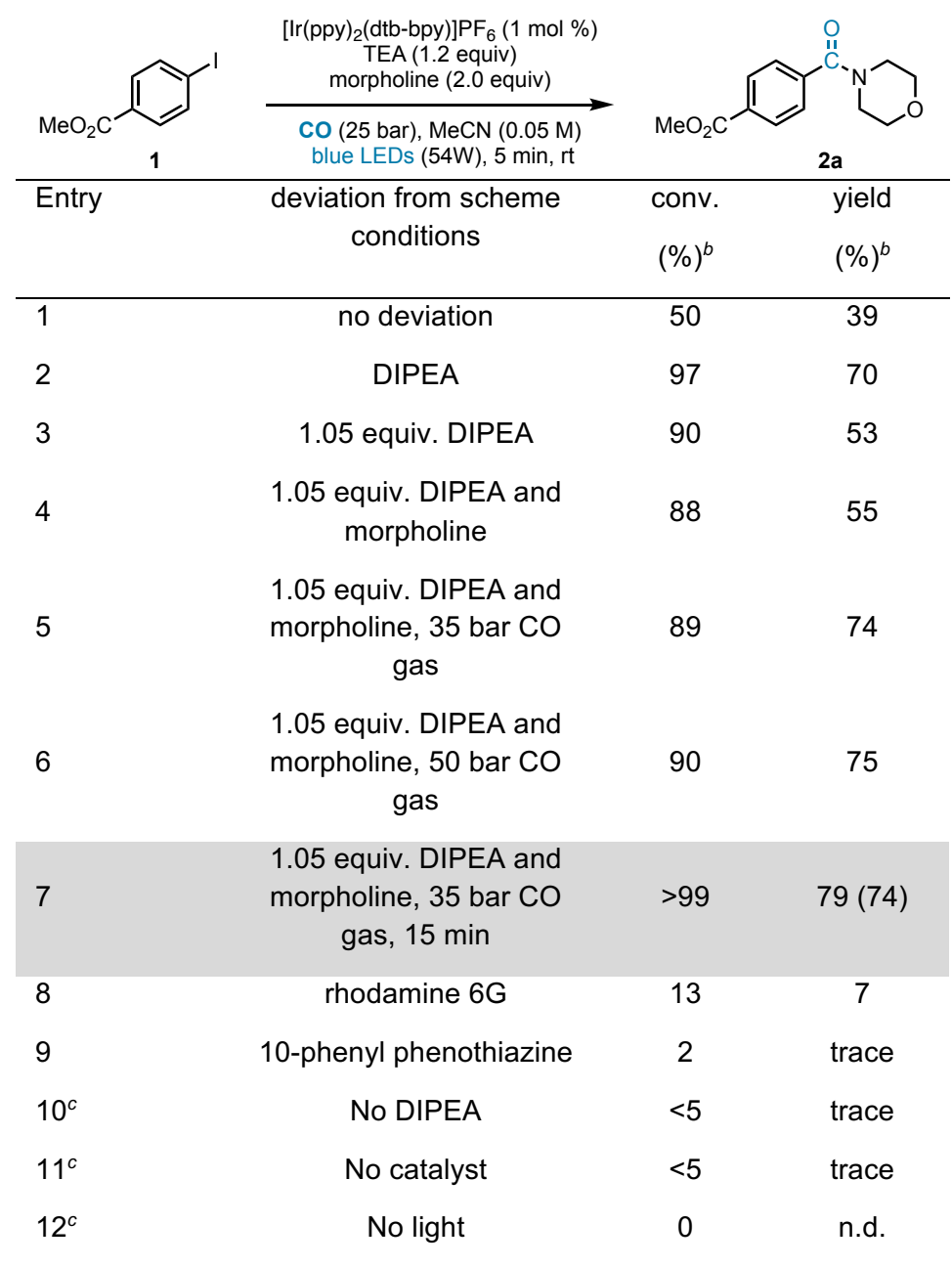

a) Unless otherwise noted, reactions were carried out with 1 ( $0.25 \mathrm{mmol})$, [lr(ppy)2(dtbbpy)]PF6 (1 mol \%), DIPEA (2.0 equiv.), morpholine (2.0 equiv.), MeCN ( $5 \mathrm{~mL}), \mathrm{CO}$ (25 bar), 54W blue LED irradiation, room temperature, 5 min photoreactor residence time. b)Determined by $1 \mathrm{H}$ NMR analysis with 1,3,5-trimethylbenzene as the internal standard. Isolated yields are given in parentheses. c) $\mathrm{CO}$ (35 bar).

Following optimization of the reaction parameters, 1.05 equivalents of $N, N$-diisopropylethylamine (DIPEA), morpholine (2 equiv.), 35 bar $\mathrm{CO}$ gas pressure and $15 \mathrm{~min}$ residence time in the photoreactor furnished the amide $2 \mathrm{a}$ in $74 \%$ yield with quantitative conversion of the aryl halide (Table 1, entry 7). Competitive protodehalogenation was a secondary reaction pathway, with methyl benzoate accounting for the remainder of the mass balance. Increasing the $\mathrm{CO}$ pressure above 35 bar did not appreciably increase the yield of 2a (Table 1, entry 6). As expected, DIPEA, the Ir photocatalyst and blue light irradiation were essential for the transformation (Table 1, entry $10-12$ ). Similarly, organo-photoredox catalysts which are not expected to promote the generation a second highly reducing excite state equivalent to Ir2 were significantly less active (Table 1, entry 8 and 9).

With the optimized reaction conditions in hand, we probed the reaction scope with respect to aryl halides (Table 2). Electron deficient aryl iodides and bromides afforded their corresponding amide products in good to excellent isolated yields (2a-11b). Aryl bromides and electron rich aryl halides required a slight increase in DIPEA (1.2 or 1.5 equiv.), morpholine (1.2 equiv.) and residence time (30 $\mathrm{min}$ ) to achieve full conversion. To suppress protodehalogenation at elevated concentrations of DIPEA and morpholine, the CO pressure was raised to 45 bar. We rationalized that elevated pressures of $\mathrm{CO}$ would favor formation of the acyl radical instead of hydrogen atom abstraction by the aryl radical. 4-Bromoacetophenone did not furnish the amide functionalized acetophenone $4 \mathbf{b}$, 
instead reduction of the carbonyl functional group was observed, with the amide functionalized a-methylbenzyl alcohol recovered as the isolated major product.

Significantly, aryl bromides could be selectively carbonylated in the presence of boronates (10), demonstrating exquisite orthogonality to Pd-catalyzed carbonylative amidation where the Suzuki coupling typically dominates ${ }^{20}$ Deactivated substrates bearing electron donating substitution were well tolerated (12a-20) and steric sensitivity to ortho-methyl substituent was generally not observed (12-14). Under the developed reaction conditions, full conversion of the starting aryl halide was achieved for each example. Notably, when 4-bromothioanisole ( $\mathrm{E}_{\mathrm{p}}^{\text {red }}=-2.54 \mathrm{~V}$ vs SCE) was subjected to the same reaction conditions using fac- $\operatorname{Ir}(\mathrm{ppy})_{3}$ in $\operatorname{lieu}$ of $\left[\operatorname{lr}(\mathrm{ppy})_{2}(\mathrm{dtb}-\mathrm{bpy}) \mathrm{PF}_{6}\right.$, no conversion was observed. This ably demonstrates the greater potential of tandem visible light photoredox catalysis to engage energy demanding substrates beyond the capabilities of a conventional photoredox cycle. The reaction was extended to the ambient temperature amidation of methyl 4-chlorobenzoate which generated the amide (2c) in $27 \%$ yield. Although sluggish via this method, the carbonylation of aryl chlorides at ambient temperature via conventional transition metal catalysis has not been realized due to the high energy barrier for oxidative addition of the transition metal catalyst to aryl chloride. ${ }^{21}$ We are currently investigation conditions to accelerate the reduction of aryl chlorides using tandem photoredox catalysis. Notably, the method was compatible with electron-rich and deficient heteroaryl halides (21a-22).

We next examined the generality of amines in the carbonylative amidation of bromobenzene (Table 2). The method afforded the corresponding aryl amide products in good to excellent yield (55-79\%) with a strong preference for secondary aliphatic cyclic amines (11b, 24-25) and secondary acyclic amines (26). Primary aliphatic amines were tolerated (27-30) although an increase of equivalents of $n$-hexyl amine and tert-butyl amine $(27,29)$ was necessary to achieve full conversion. Allyl amine, containing a terminal alkene that is susceptible to radical addition by ary $\mathrm{l}^{22}$ and alky $\left.\right|^{23}$ acyl radicals, gave $\mathbf{3 1}$ without unwanted substitution or polymerization by-products. The developed reaction was further applied to a radical addition/aminocarbonylation cascade reaction. The biscarbonylated $\alpha$-keto amide $\mathbf{2 3}$ was the dominant reaction product. Synthetic access to the methylene $\alpha$-keto amide motif is not readily accessible by Pd-catalyzed carbonylative methodology owing to the uncontrollable generation of carbonylated by-products. ${ }^{24}$ Finally, we demonstrate the straightforward scalability of the method by processing $10 \mathrm{mmol}$ of bromobenzene to afford $1.8 \mathrm{~g}$ of $2 \mathrm{a}$ in $72 \%$ isolated yield.

\section{Aminocarbonylation of Alkylhalides}

We next turned our attention to the carbonylative amidation of alkyl iodides. For this study, we assembled a bespoke flow platform from commercially available components to demonstrate how non-specialist laboratories can access flow methodology as a strategy for photochemical carbonylation. The flow chemistry platform consists of a Knauer ${ }^{\circledR}$ Smartline pump (although any syringe or HPLC pump capable of high pressure handling can be deployed), an Upchurch ${ }^{\circledR} 6$ port injection valve, a tube-in-tube gas/liquid reactor assembled and bespoke flow photoreactor fabricated in our laboratory (Supplementary Fig S3 and Fig S4). The method was reoptimized for the carbonylative amidation of alkyl iodides and the synthesis of cyclohexylamide $(43)$ using iodocyclohexane $\left(E_{p}{ }^{\text {red }}=-\right.$ $2.15 \mathrm{~V}$ vs SCE $)^{15}$ as a representative alkyl iodide substrate. In line with the aryl halides, we selected morpholine as the amine coupling partner, DIPEA as sacrificial reductant and the $\left[\operatorname{Ir}(\mathrm{ppy})_{2}(\mathrm{dtb}-\mathrm{bpy})\right] \mathrm{PF}_{6}$ photocatalyst. Optimization of the reaction parameters required 1.05 equivalents of DIPEA, 2 equivalents of the alkyl iodide, 15 bar $\mathrm{CO}$ gas pressure and 20 min residence time (in the photoreactor) to afford amide $\mathbf{4 3}$ in $96 \%$ yield (see supplementary information).

Next, we focused attention on the generality of the carbonylative amidation of alkyl iodides. As shown in Table 3, tertiary morpholinoamides are obtained in excellent yields for tertiary, secondary, and primary iodides. A notable feature of this method is the tolerance of primary alkyl iodides, which can be difficult to reduce via photoinduced electron transfer (PET) via conventional Ir photocatalysts owing to their negative redox potential $\left(E_{n-B u l}=-2.33 \mathrm{~V} \text { vs } S C E\right)^{25}$ and the intrinsic reactivity between primary alkyl iodides and amines in a $S_{N} 2$ reaction. ${ }^{12 a, b}$ Exceptional selectivity for carbonylative amidation of primary alkyl iodides is observed using this tandem photoredox method, affording the corresponding desired amide products in yields up to $96 \%$ (41). The compatibility of amines in this transformation was next investigated (Table 3). Firstly, a series of aliphatic amines were examined. Saturated cyclic secondary 
amines smoothly furnished the corresponding amides in excellent yield (44-50), although acyclic amines are sensitive to steric hinderance (51). Primary amines were all competent including amines appended to cyclic and acyclic hydrocarbons (52-54) as well as allylic, propargylic and benzylamines (55-57). Interestingly, ethanolamine afforded the amide (58) exclusively without competitive esterification. We were also very pleased to observe product formation with aminoacids, where previous reports only detected trace amounts of the desired amide for very similar substrates (59). ${ }^{12 a}$

Table 2. Aryl halide and amine scope ${ }^{a}$

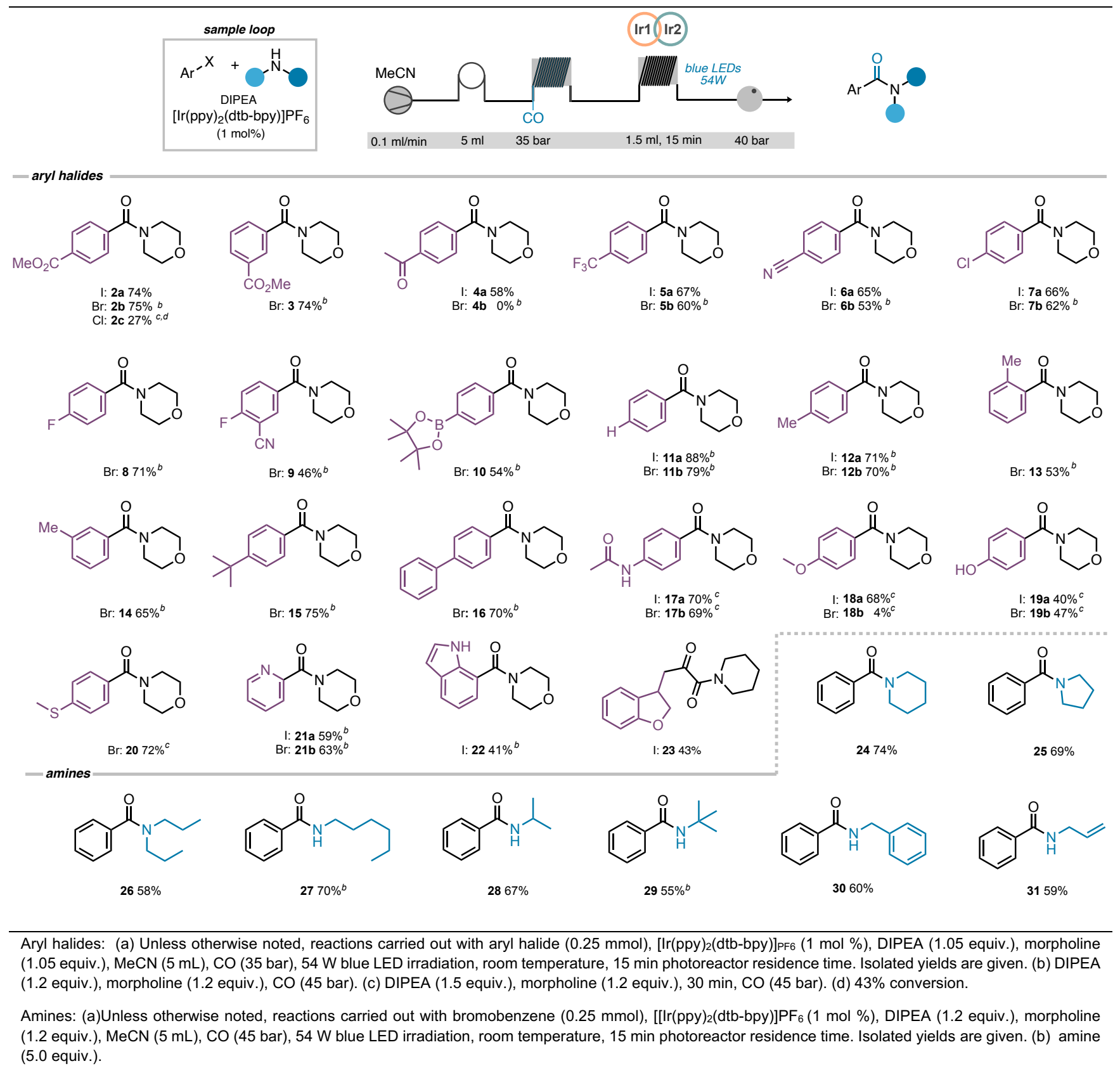

The next phase of the study investigated the compatibility of anilines as the amine component. Optimal yields were obtained with an increased equivalent of DIPEA. In general, the yields were insensitive to the presence of electron withdrawing or donating substituents, however electron rich anilines marginally improved yield (60-65). The aryl amines with extended conjugation, 1aminonaphthyl (74) and 8-aminoquinoline (75), were tolerated with the latter establishing a simple approach to access novel 8- 
aminoquinoline derivatives relevant to auxiliary directed $\mathrm{C}-\mathrm{H}$ activation strategies. ${ }^{26}$ Importantly, across all of these examples, the aryl and alkyl halides were reliably reduced by $\left(\mathbf{I r} \mathbf{2}^{*}\right)$ in the presence of other functional groups capable of undergoing single electron reduction. Notably, the halogenated substrates afforded the desired product (66-69) in excellent yields and with exceptional chemoselectivity despite propensity for protodehalogenation under similar conditions. ${ }^{27}$ Importantly, the orthogonality of the tandem photoredox reaction to Pd-catalyzed carbonylative amidation is highlighted by the unreactivity of the halides for substrates (66-69).

A further demonstration of synthetic utility is demonstrated through the preparation of cholesterol amides (42) in good to excellent yields via the iodinated cholesterol (Table 3). The amides were obtained in 1:1 dr and 42c-e were isolated as the enantiopure diastereoisomers following chromatographic purification. The operational simplicity and practicality of the method is exemplified through the scaled up carbonylative amidation of $\mathbf{4 8}$ (Scheme 1) without erosion of yield. The standard conditions were used with two minor adjustments; the reactor volume was increased to $6 \mathrm{~mL}$ and a FlowIR ${ }^{\circledR}$ unit was used to monitor the reaction. The reaction was run continuously giving $5.17 \mathrm{~g}$ of the desired in $75 \%$ yield, based on steady state collection.

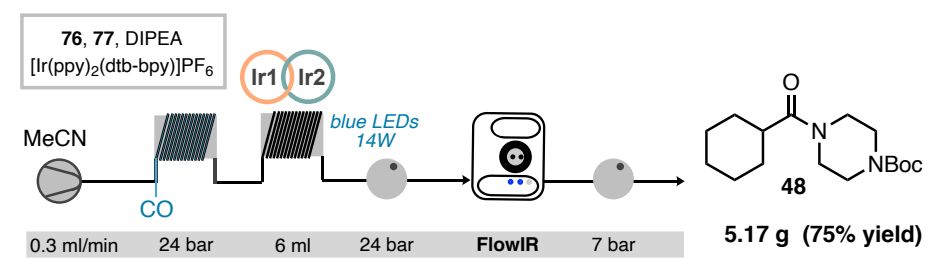

Scheme 1: Reaction scale-up. Conditions: N-Boc-piperidine 76 (0.1M) iodocyclohexane 77 (2 equiv.), DIPEA (1.05 equiv.), $\left[\operatorname{lr}(\mathrm{ppy})_{2}(\mathrm{dtb}-\mathrm{bpy})\right] \mathrm{PF} 6(1 \mathrm{~mol} \%)$.

\section{Mechanistic studies}

Experimental and theoretical approaches were utilized to study the reaction mechanism. Firstly, we probed the mechanism of the photocatalytic cycle with aryl halides. Control experiments established in the optimization studies support the operation of a photocatalytic process through dependence on the $\left[\operatorname{Ir}(\mathrm{ppy})_{2}(\mathrm{dtb}-\mathrm{bpy})\right] \mathrm{PF} 6$ photocatalyst and blue light irradiation (Table 1, entry 11-12). The control experiments further support the operation of a tandem photoredox cycle where the generation of the second excited-state Ir2 ${ }^{*}$ is dependent on the addition of a tertiary amine reductant with labile $\alpha$-hydrogens (Table 1 , entry 10 ). ${ }^{15}$ For a more detailed exploration of the mechanism, spectroscopic measurements of key intermediates were performed (Supplementary Fig S9 to S15). Spectroscopy measurements with LED irradiation $(\lambda=445 \mathrm{~nm})$ of a solution containing $0.1 \mathrm{mM}$ Ir1 and $50 \mathrm{mM}$ DIPEA resulted in the rapid formation of $\operatorname{Ir} 1^{-}\left(\lambda_{\text {abs }}=530 \mathrm{~nm}\right)^{15}$ followed by exponential decay and the concomitant increase in emission intensity attributable to $\operatorname{Ir2}^{*}\left(\lambda_{\mathrm{em}}=510 \mathrm{~nm}\right)^{15}$ and consonant with the characterization of Ir2* under similar reaction conditions (Scheme $\left.2 b(\mathrm{i})\right)$. When the measurements were repeated with the addition of methyl 4-iodobenzoate (1) ( $E_{p}{ }^{\text {red }}=-1.78 \vee$ vs SCE), absorption or emission attributable to either intermediate was not observed, suggesting rapid oxidation of Ir1' to Ir1 via electron transfer to methyl 4-iodobenzoate (Supplementary Fig S12 and S13). Substituting 1 for 4-bromothioanisole S4 ( $E_{p}{ }^{\text {red }}=-2.54$ vs SCE), formation of Ir1was observed along with emission assigned to Ir2 ${ }^{*}$, albeit with a significantly lower intensity as Ir1' is not quenched by the more difficult to reduce bromide substrate (Supplementary Fig S14 and S15). We further confirmed this interaction between 4-bromothioanisole (S4) and Ir2* using steady state emission quenching experiments (Supplementary Fig S17). In line with the aryl halides, spectroscopic measurements show that the addition of iodocyclohexane $\left(E_{p}{ }^{\text {red }}=-2.15 \mathrm{~V} \text { vs SCE}\right)^{15}$ reduced the emission intensity of excited-state $\mathbf{I r 2}{ }^{*}$ $\left(\lambda_{\mathrm{em}}=510 \mathrm{~nm}\right)^{15}$ suggesting electron transfer to the alkyl iodide (Scheme $\left.2 \mathrm{~b}(\mathrm{ii})\right)$. Furthermore, absorption for Ir1- $\left(\lambda_{\mathrm{abs}}=530 \mathrm{~nm}\right)^{15}$ was observed concurrent to emission assigned to Ir2 ${ }^{*}$, with the addition of iodocyclohexane and that evidences reduction from Ir ${ }^{*}$ and not directly from Ir1' (Scheme $2 \mathrm{~b}(\mathrm{iii})$ ). This electron transfer pathway was further confirmed by Stern-Volmer quenching studies of Ir2* with iodocyclohexane (Scheme 2b(iv)). 
Table 3: Scope of alkyl iodide and amines.
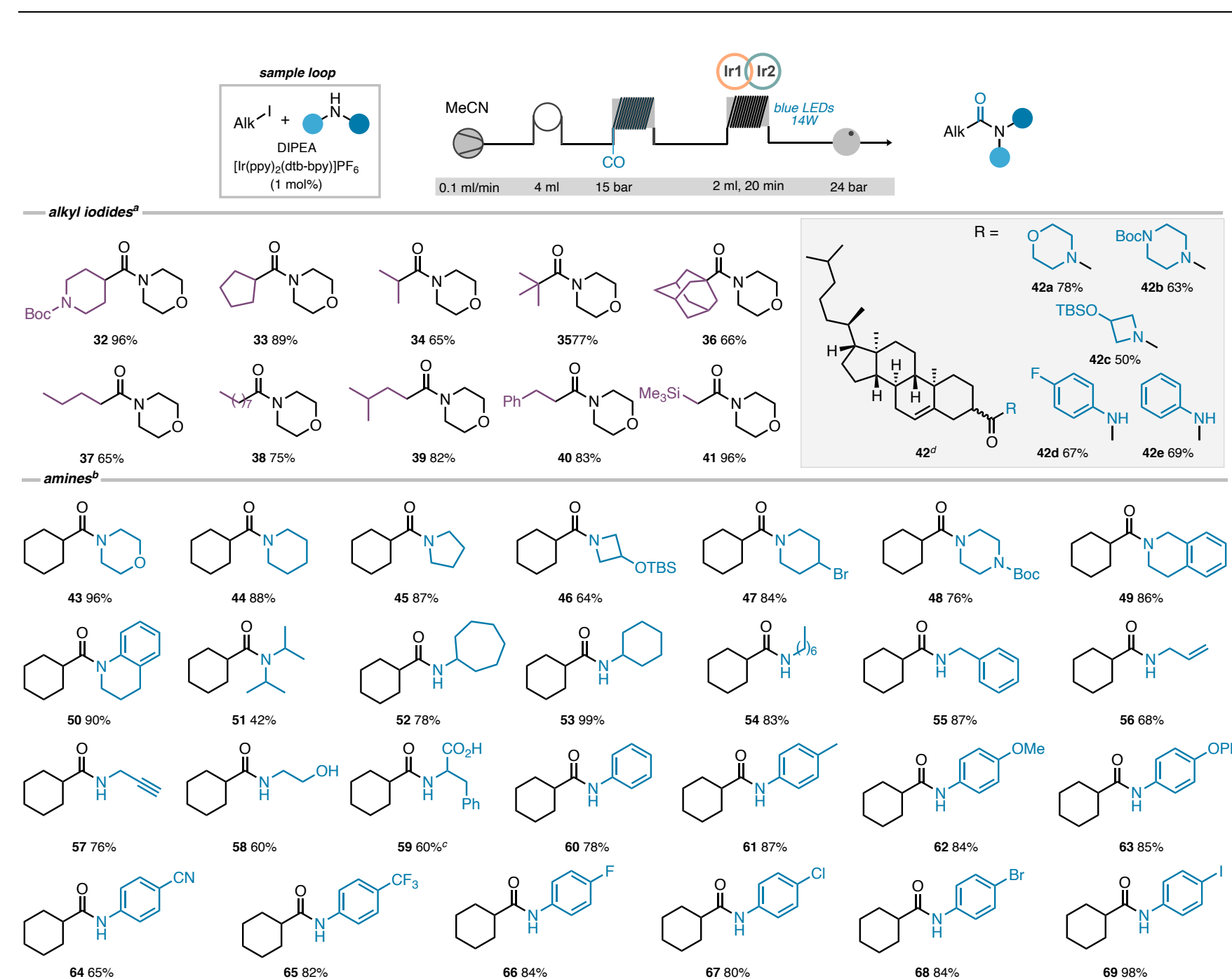

$5860 \%$

$5960 \%^{c}$<smiles>O=C(C1CCCCC1)N1CCC(Br)CC1</smiles>

$4784 \%$<smiles>CC(C)(C)OC(=O)N1CCN(C(=O)C2CCCCC2)CC1</smiles>

$4876 \%$<smiles>O=C(C1CCCCC1)N1CCc2ccccc2C1</smiles>

$4986 \%$<smiles>CCNC(=O)C1CCCCC1</smiles>

$5483 \%$<smiles>Cc1ccc(NC(=O)C2CCCCC2)cc1</smiles>

$6187 \%$<smiles>O=C(NCc1ccccc1)C1CCCCC1</smiles>
$5587 \%$<smiles>COc1ccc(NC(=O)C2CCCCC2)cc1</smiles>
$6284 \%$<smiles>C=CCNC(=O)C1CCCCC1</smiles><smiles>O=C(Nc1ccc(O)cc1)C1CCCCC1</smiles><smiles>CC(=O)c1ccc(NC(=O)C2CCCCC2)cc1</smiles>

70 99\% $7179 \%$<smiles>O=C(Nc1ccc(F)cc1)C1CCCCC1</smiles>

$6684 \%$<smiles>O=C(Nc1ccc(Cl)cc1)C1CCCCC1</smiles><smiles>CC(C)(C)OC(=O)c1ccc(NC(=O)C2CCCCC2)cc1</smiles>

$6884 \%$<smiles>O=C(Nc1ccc(I)cc1)C1CCCCC1</smiles><smiles>COC(=O)c1ccc(NC(=O)C2CCCCC2)cc1</smiles><smiles>O=C(c1ccccc1)c1ccc(NC(=O)C2CCCCC2)cc1</smiles><smiles>O=C(Nc1cccc2ccccc12)C1CCCCC1</smiles><smiles>O=C(Nc1cccc2cccnc12)C1CCCCC1</smiles>

Unless otherwise noted, reactions carried out with alkyl halide (2.0 equiv.), [Ir(ppy)2(dtb-bpy)]PF 6 (1 mol \%), DIPEA (1.05 equiv.), amine (0.40 mmol), MeCN (4 $\mathrm{mL}$ ), CO (15 bar), 14W blue LED irradiation, room temperature, 20 min photoreactor residence time. Isolated yields are given. a) Conditions for primary alkyl iodides: alkyl iodide (2.5 equiv.), DIPEA (3.0 equiv.), $40 \mathrm{~min} \mathrm{t}_{\mathrm{r}}(4 \mathrm{~mL}$ reactor volume). b) DIPEA (3.0 equiv. for $60-75)$. c) $\mathrm{MeOH} / \mathrm{H}_{2} \mathrm{O}(9: 1) \mathrm{solvent}$ system, DIPEA (3.0 equiv.). d) solvent: toluene/MeCN (3:2), DIPEA (1.05 equiv. for $\mathbf{4 2 a}$, 42 and $42 c$; 3.0 equiv. for $42 \mathrm{~d}$ and $\mathbf{4 2 e}$ ), $0.05 \mathrm{M}$ concentration, 40 min tr (4 $\mathrm{mL}$ reactor volume).

A plausible mechanism for the generation of aryl and alkyl radicals from organohalides by visible light tandem photoredox catalysis is shown in Scheme 2. Visible light excitation of Ir1 generates excited-state Ir1* and reductive quenching with DIPEA generates the reductant I $\mathbf{r} 1^{-}$and DIPEA ${ }^{*+}$. In the presence of energy demanding organohalides, electron transfer from Ir1 ${ }^{-}$is thermodynamically unfavorable and hydrogen atom transfer (HAT) from DIPEA ${ }^{*+}$ to Ir1' dominates. The resulting HAT generates Ir2 containing a semisaturated (dtb-bpy) ligand and initiates the second Ir photocatalytic cycle (Ir-2). Absorption of blue light by Ir2 produces the highly reducing excited state catalyst Ir2*, which has a reduction potential $\left(E^{\circ}\left(\operatorname{Ir} 2^{+} / / r 2^{*}\right)=-1.70\right.$ to $-3.00 \mathrm{~V}$ vs SCE), below Ir1* and Ir1. The 
energy demanding organohalides are subsequently reduced by Ir2* via electron transfer to generate an aryl or alkyl radical and Ir2 ${ }^{+}$. The catalytic cycle is closed by the reduction of Ir2+ ${ }^{+}$by Ir1 ${ }^{-}$or DIPEA* (via DIPEA ${ }^{*+}$ ). Finally, Ir1 may be regenerated following hydrogen atom transfer from Ir $\mathbf{2}^{+}$to acceptors such as aryl and alkyl radicals or the acyl radical $(\mathbf{8 0})$.

We next considered the fate of the acyl radicals which are converted to the product via three possible pathways (Scheme 2c). In Path A, single electron oxidation of the acyl radical by the oxidized photocatalyst $\operatorname{Ir} 2^{+}\left(\mathrm{E}_{1 / 2}\left(\operatorname{Ir} \mathbf{2}^{+} / \mathbf{I r} 2\right)=+0.88 \mathrm{~V}\right.$ vs SCE) results in the formation of the electrophilic acylium ion $\mathbf{8 1} .{ }^{13}$ For arene derived radicals, the calculated DFT (B3LYP/6-311+G(g,p)) oxidation potentials of the resulting acyl radical were estimated to be -0.11 to $+0.36 \vee$ vs SCE (Supplementary Table S1) depending on substitution on the aromatic ring, suggesting electron transfer is thermodynamically favorable. Similarly, the DFT estimated oxidation potentials of alkyl acyl radicals is approximately $0.0 \mathrm{~V}$ vs SCE suggesting generation of acylium ion (81) from the alkyl iodides is also favorable (Scheme $2 \mathrm{c}(\mathrm{i})$ ). Subsequent reaction of the electrophilic acylium ion with the amine affords the amide. In Path $\mathbf{B}$ halogen atom abstraction by the acyl radical (80) to form an acyl halide ${ }^{11 a}, 28$ is followed by nucleophilic addition of the amine. In path $\mathbf{A}$ and $\mathbf{B}$, the generation of an electrophilic acylium ion $\mathbf{8 1}$ or acyl halide (82) is necessary to promote nucleophilic addition of the amine. However, with the replacement of an amine with alcohol nucleophiles, low yields of the ester were observed for both aryl and alkyl halides (Scheme 2 c(ii)). The insensitivity to alcohol nucleophiles suggests that paths $\mathbf{A}$ and $\mathbf{B}$ are not the dominant processes in this carbonylative amidation. A third mechanism, Path $\mathbf{C}$ proceeds via nucleophilic addition of the amine to the acyl radical giving the $\alpha$ hydroxy radical 83 via amine-assisted intermolecular proton transfer ${ }^{29}$ Formation of the amide proceeds via oxidation of $\alpha$-hydroxy radical $(\mathbf{8 3})$ by the $\mathbf{I r 2 ^ { + }}$ catalyst or by radical chain propagation. The oxidation potential of a series of hydroxybenzyl and hydroxyalkyl radical species (83) was estimated by DFT calculations (Supplementary Table S1) and the oxidation of these intermediates by Ir2 ${ }^{+}$ catalyst is thermodynamically feasible. Ryu and coworkers have reported that hydroxybenzyl radical species (83) undergo radical chain propagation with the aryl iodides that is accompainied with a highly endothermic $(\Delta \mathrm{H}=52.1 \mathrm{~kJ} / \mathrm{mol}) \mathrm{SET}$ to the aryl halide. ${ }^{30} \mathrm{However}$, net amide formation is largely exothermic and predicted to be spontaneous $(\Delta \mathrm{H}=-80 \mathrm{~kJ} / \mathrm{mol}),{ }^{30}$ demonstrating that formation of the strong amide bond is the driving force for this process.

Within the context of alkylhalides, our DFT studies support spontaneous electron transfer from $\alpha$-hydroxalkyl radical (83) to the alkyl iodide $(\Delta \mathrm{G}=-43 \mathrm{kcal} / \mathrm{mol}, \Delta \mathrm{H}=-167 \mathrm{~kJ} / \mathrm{mol}$; Scheme $2 \mathrm{c}$ (iii). On the basis of these mechanistic studies reported herein, we assign formation of the amide product via the radical propagation sequence in Path $\mathbf{C}$. 
Tandem photoredox cycle

a)

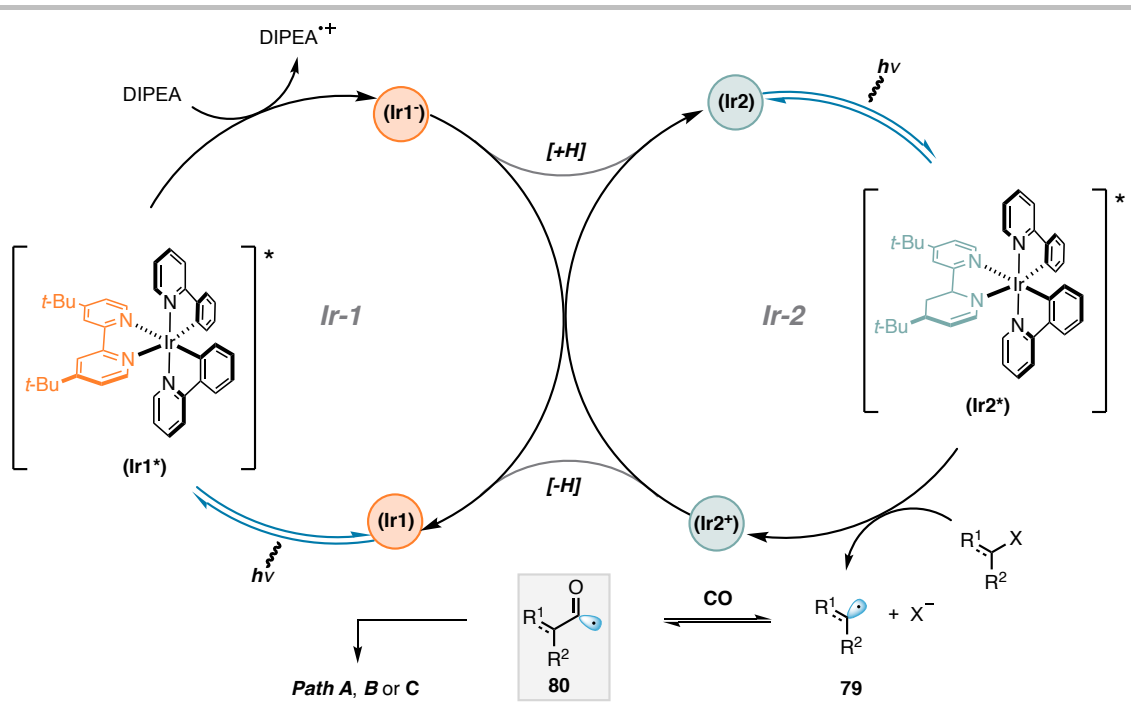

b) (i)

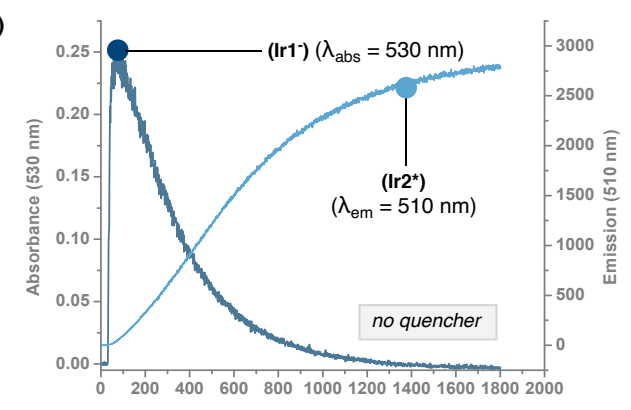

(iii)

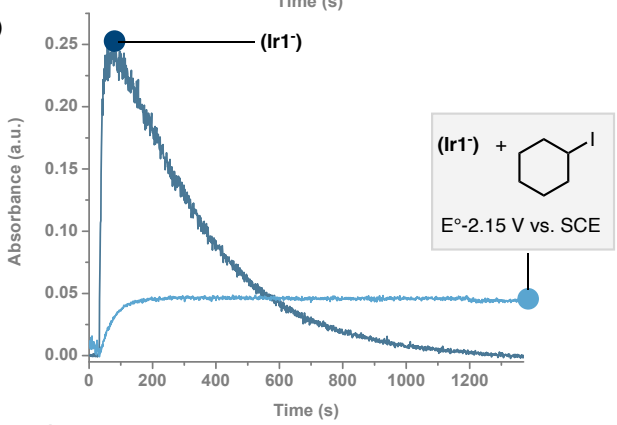

c)

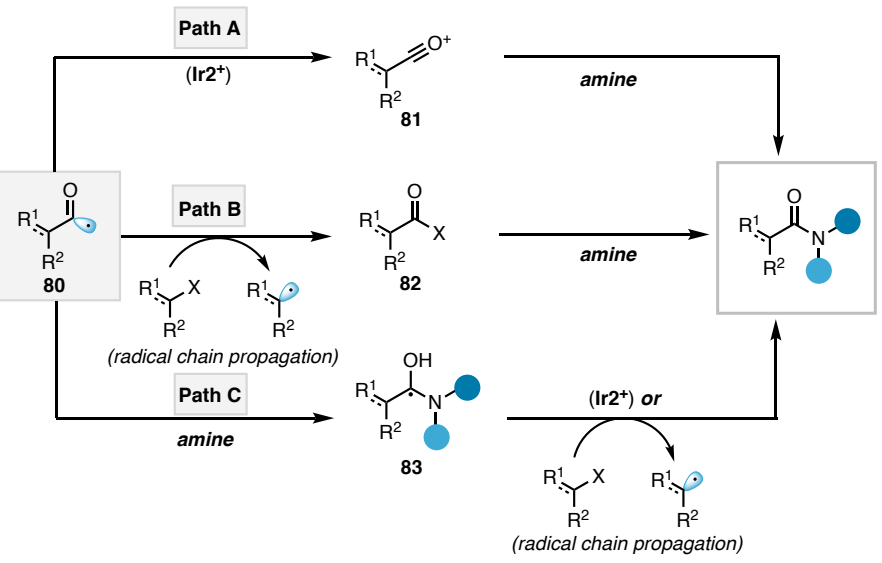

(ii)

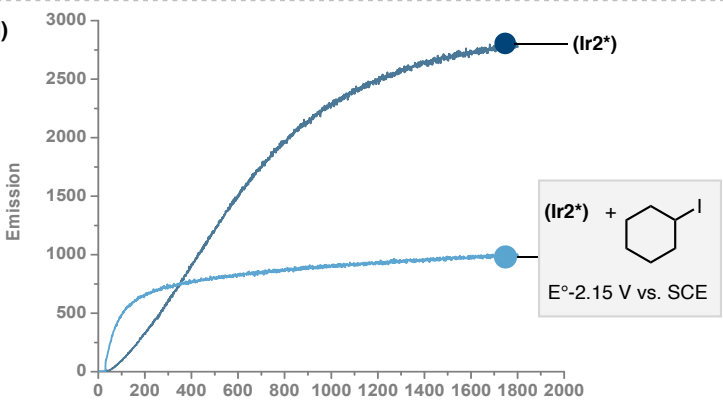

(iv)

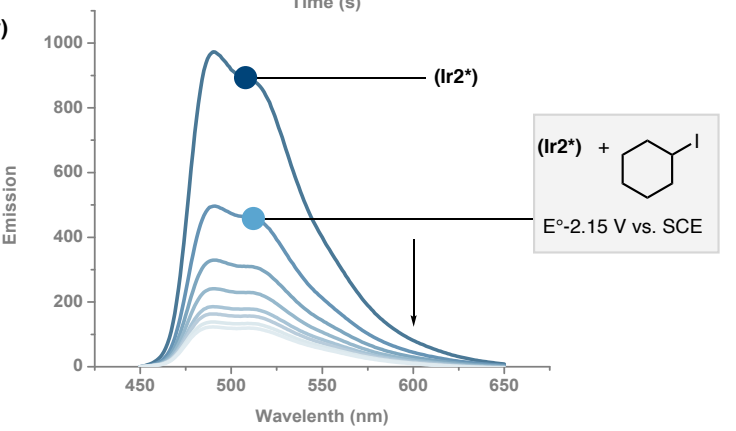

d) (i) DFT calculations supporting Path A:

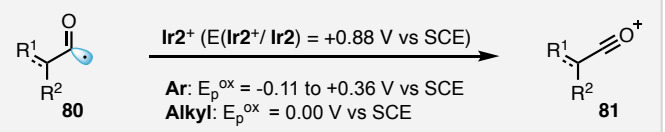

(ii) Mechanistic evidence not supporting Path A or Path B:

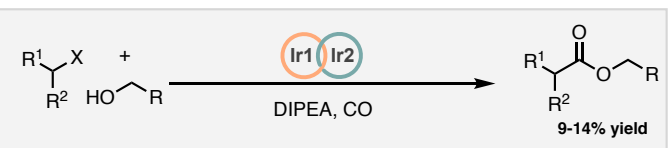

(iii) DFT calculations supporting Path C:

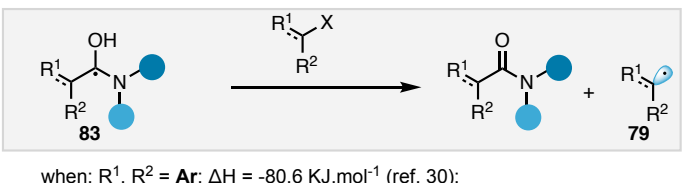

when: $R^{1}, R^{2}=A r: \Delta H=-80.6 \mathrm{KJ}^{2} \mathrm{~mol}^{-1}($ ref. 30 );

Scheme 2. a) Single electron reduction of aryl and alkyl halides by the tandem photoredox cycle of $\left[\operatorname{Ir}\left(\text { ppy) }{ }_{2} \text { (dtb-ppy) }\right]^{+}\right.$. b) Spectroscopic studies: (i) absorbance of Ir1* and emission of Ir2* in the absence of the organohalide quencher, monitored at $530 \mathrm{~nm}$ and at $510 \mathrm{~nm}$, respectively. (ii) Emission of Ir2* in the absence, and presence of iodocyclohexane. (iii) Absorbance of Ir1* in the absence and presence of iodocyclohexane.(iv) Quenching experiments of Ir2* by iodocyclohexane. c) Plausible reaction pathways for conversion of the acyl radical into the amide product. d) Mechanistic investigations: (i) DFT determination of the redox potential of aryl and alkyl acyl radicals. (ii) Control experiment with an alcohol nucleophile. (iii) DFT determination of reaction enthalpies for the radical chain propagation step. 
Forni et al.

\section{Conclusion}

In summary, we have developed a new light-mediated protocol for the carbonylative amidation of energy demanding organohalides. This transformation exploits the unique tandem photocatalytic cycle of $\left[\operatorname{Ir}(\mathrm{ppy})_{2}(\mathrm{dtb}-\mathrm{bpy})\right]^{+}$, which engages aryl bromides, iodides and chlorides as well alkyl iodides to generate aryl, heteroaryl and alkyl amides using carbon monoxide as $\mathrm{C} 1$ building block. The versatility of the method is demonstrated by compatibility with primary, secondary and tertiary amines in addition to high functional group tolerance, enabling the generation of synthetically useful and pharmaceutically relevant amides, and the late stage functionalization of complex biologically active compounds. The application of continuous flow processing affords an operational ease, safety and scalability suitable for integration in both academic and industrial laboratories.

\section{References}

(1) (a) Pattabiraman, V. R.; Bode, J. W. Rethinking amide bond synthesis. Nature 2013, 480, 471-479. (b) Sabatini, M. T.; Boulton, L. T.; Sneddon, H. F.; Sheppard, T. D. A green chemistry perspective on catalytic amide bond formation. Nat. Catal. 2019, 2, 10-17. (c) Mahjour, B.; Shen, Y.; Liu, W.; Cernak, T. A map of the amine-carboxylic acid coupling system. Nature 2020, 580, 71-75.

(2) Marchildon, K. Polyamides - still strong after seventy years. Macro. React. Eng. 2010, 5, 22-54.

(3) Lamberth, C.; Jeanmart, S.; Luksch, T.; Plant, A. Current challenges and trends in the discovery of agrochemicals. Science 2013, $341,742$.

(4) (a) Bodanszky, M.; Bodanszky, A. The practice of peptide synthesis. Berling, Heidelberg, Springer, 1994. (b) Marder, O.; Albericio, F. Industrial application of coupling reagents in peptides. Chim. Oggi 2003, 21, 6-11.

(5) Humprey, J. M.; Chamberlin, A. R. Chemical synthesis of natural product peptides: coupling methods for the incorporation of noncoded amino acids into peptides. Chem. Rev. 1997, 97, 2243-2266.

(6) (a) Isidro-Llobet, A.; Suppo, J.-S. Sustainability challenges in peptide synthesis and purification: from R\&D to production. J. Org. Chem. 2019, 84, 4615-4628. (b) Constable, D. J. C.; Dunn, P. J.; Hayler, J. D.; Humphrey, G. R.; Leazer, J. L., Jr; Linderman, R. J.; Lorenz, K.; Manley, J.; Pearlman, B. A.; Wells, A.; Zaks, A.; Zhang, T. Y. Key green chemistry research areas-a perspective from pharmaceutical manufacturers. Green Chemistry 2007, 9, 411-420.

(7) (a) de Figueiredo, R. M.; Suppo, J.-S.; Campgane, J.-M. Nonclassical routes for amide bond formation Chem. Rev. 2016, 116, 12029-12122. (b) Atkinson, B. N. Chhatwal, A. R.; Willians, J. M.J. Applied Homogenous Catalysis with Organometallic Compounds: A Comprehensive Handbook. Ch. 27 Catalytic Amide Bond Forming Methods, Willey-VCH GmbH \& Co. KGaA, Weiheim, 2018. (c) Lundberg, H.; Tinnis, F.; Selander, N.; Adolfsson, H. Catalytic amide formation from non-activated carboxylic acids and amines. Chem. Soc. Rev. 2014, 43, 2714-2742

(8) (a) Brennführer, A.; Neumann, H.; Beller, M. Palladium-catalyzed carbonylation reactions of aryl halides and related compounds. Angew. Chem. Int. Ed. 2009, 48, 4114-4113. (b) Shen, C.; Wu, X.-F. Palladium-catalyzed carbonylative multicomponent reactions. Chem. Eur. J. 2017, 23, 2973-2987.

(9) (a) Grigg, R.; Mutton, S. P. Pd-catalyzed carbonylations: versatile technology for discovery and process chemists. Tetrahedron 2010, 66 , 5515-5548. (b) Hartwig, J. Organotransition Metal Chemistry: From Bonding to Catalysis Ch. 7,University Science Books: Sausalito, CA, 2010, pp. 301-320.

(10) Wu, L.; Fang, X.; Liu, Q.; Jackstell, R.; Beller, M.; Wu, X.-F. Palladium-Catalyzed Carbonylative Transformation of C(sp $\left.{ }^{3}\right)-X$ bonds. ACS Catal. 2014, 4, 2877-2989.

(11) (a) Ryu, I.; Nagahara, K.; Kambe, N.; Sonoda, N.; Kreimerman, S.; Komatsu, M. Metal catalyst-free by design. The synthesis of amides from alkyl iodides, carbon monoxide and amines by a hybrid radical/ionic reaction. Chem. Commun. 1998, 1953-1954. (b) Chow, S. Y.; Odell, L. R.; Eriksson, J. Low-pressure radical 11c-aminocarbonylation of alkyl iodides through thermal initiation, Eur. J. Org. Chem. 2016, 5980-5989. (c) Ryu, I. Radical carboxylations of iodoalkanes and saturated alcohols using carbon. Chem. Soc. Rev.

2001, 30, 16-25. (d) Sumino, S.; Fusano, A.; Fukuyama, T.; Ryu, I. Carbonylation reactions of alkyl iodides through the interplay of carbon radicals and Pd catalysts Acc. Chem. Res. 2014, 47, 1563-1574. 
(12) (a) Chow, S. Y.; Stevens, M. Y.; Åkerbladh, L.; Bergman, S.; Odell, L. R. Mild and low-pressure fac-Ir(ppy)3-mediated radical aminocarbonylation of unactivated alkyl iodides through visible-light photoredox catalysis Chem. Eur. J. 2016, 22 , 9155-9161. (b) Sardana, M.; Bergman, J.; Ericsson, C.; Kingston, L. P.; Schou, M.; Dugave, C.; Audisio, D.; Elmore, C. S. Visible-light-enabled aminocarbonylation of unactivated alkyl iodides with stoichiometric carbon monoxide for application on late-stage carbon isotope labeling. J. Org. Chem. 2019, 84, 16076-16085. (c) Cartier, A., Levernier, E., Dhimane, A.-L., Fukuyama, T., Ollivier, C., Ryu, I. and Fensterbank, L. Synthesis of Aliphatic Amides through a Photoredox Catalyzed Radical Carbonylation Involving Organosilicates as Alkyl Radical Precursors. Adv. Synth. Catal, 2020, (in press)

(13) (a) Micic, N.; Polyzos, A. radical carbonylation mediated by continuous-flow visible-light photocatalysis: access to 2,3dihydrobenzofurans. Org. Lett. 2018, 20, 4663-4666. (b) Gosset, C.; Pellegrini, S.; Jooris, R.; Bousquet, T.; Pelinski, L. Visible-lightmediated hydroxycarbonylation of diazonium salts. Adv. Synth. Catal. 2018, 360, 3401-3405. (c) Peng, J.-B.; Qi, X.; Wu, X.-F. Visible light-induced carbonylation reactions with organic dyes as the photosensitizers. ChemSusChem 2016, 9, 2279-2283.

(14) For selected examples and reviews on multi-photon excitation see (a) Barkeshli, M.; Berg, E.; Kivelson, S. Reduction of aryl halides by consecutive visible light-induced electron transfer processes. Science 2014, 346. 722-725. (b) Ravetz, B. D.; Pun, A. B.; Churchill, E. M.; Congreve, D. N.; Rovis, T.; Campos, L. M. Photoredox catalysis using infrared light via triplet fusion upconversion Nature 2019, 565, 343-346. (c) Giedyk, M.; Narobe, R.; Weiß, S.; Touraud, D.; Kunz, W.; König, B. Photocatalytic activation of alkyl chlorides by assembly-promoted single electron transfer in microheterogeneous solutions Nat. Catal. 2020, 3, 40-47. (d) Chatterjee, A.; König, B. Angew. Chem. Int. Ed. Birch-type photoreduction of arenes and heteroarenes by sensitized electron transfer 2019, 131, 14427-14432. (e) Ghosh, I.; König, B. Chromoselective photocatalysis: controlled bond activation through light-color regulation of redox potentials. Angew. Chem. Int. Ed. 2016, 55, 7675-7679. (f) Kerzig, C.; Xingwei, G.; Wenger, O. S. Unexpected hydrated electron source for preparative visible-light driven photoredox catalysis. J. Am. Chem. Soc. 2019, 141, 2122-2127. (g) Glaser, F.; Kerzig, C.; Wenger, O. S. Angew. Chem. Int. Ed. Multi-photon excitation in photoredox catalysis: concepts, applications, methods. 2020, 59, 2-21. (15) Connell, T. U.; Fraser, C. L.; Czyz, M. L.; Smith, Z. M.; Hayne, D. J.; Doeven, E. H.; Agugiaro, J.; Wilson, D. J. D.; Adcock, J. L.; Scully, A. D.; Gómez, D. E.; Barnett, N. W.; Polyzos, A.; Francis, P. S. The tandem photoredox catalysis mechanism of [ir(ppy) 2 (dtbbpy) $]^{+}$enabling access to energy demanding organic substrates. J. Am. Chem. Soc. 2019, 141, 17646-17658.

(16) MacKenzie, I. A.; Wang, L.; Onuska, N. P. R.; Williams, O. F.; Begam, K.; Moran, A. M.; Dunietz, B. D.; Nicewicz, D. A. Discovery and characterization of an acridine radical photoreductant Nature 2020, 580, 76-80.

(17) For selected reviews and examples on flow chemistry see (a) Ley, S. V.; Fitzpatrick, D. E.; Ingham, R. J.; Myers, R. M. Organic synthesis: march of the machines. Angew. Chem. Int. Ed. 2015, 54, 3449-3464. (b) Pastre, J. C.; Browne, D. L.; Ley, S. V. Flow chemistry syntheses of natural products Chem. Soc. Rev. 2013, 42, 8801-9198. (c) Hessel, V.; Kralisch, D.; Kockmann, N.; Noël, T.; Wang, Q. Novel process windows for enabling, accelerating, and uplifting flow chemistry. ChemSusChem 2013, 6, 746-789. (d) Gutmann, B.; Cantillo, D.; Kappe, C. O. Continous-flow technology-a tool for the safe manufacturing of active pharmaceutical ingredients. Angew. Chem. Int. Ed. 2015, 54, 6688-6728. (e) Webb, D.; Jamison, T. F. Continuous flow multi-step organic synthesis. Chem. Sci. 2010, 1, 675-678. (f) Plutschack, M. B.; Pieber, B.; Gilmore, K.; Seeberger, P. H. The hitchhiker's guide to flow chemistry Chem. Rev. 2017, 117, 11796-11893. (g) Baxendale, I. R. The integration of flow reactors into synthetic organic chemistry. J. Chem. Technol. Biotechnol. 2013, 88, 519-552. (h) Howard, J. L.; Schotten, C.; Browne, D. L. Continuous flow synthesis of antimalarials: opportunities for distributed autonomous chemical manufacturing. React. Chem. Eng. 2017, 2, 281-287. (i) Tsubogo, T.; Oyamada, H.; Kobayashi, S. Multistep continuous-flow synthesis of (R)- and (S)-rolipram using heterogeneous catalysts Nature 2015, 520, $329-332$. (18) For selected reviews and applications of the tube-in-tube reactors see (a) O'Brien, M.; Baxendale, I. R.; Ley, S. V. Flow ozonolysis using a semipermeable Teflon af-2400 membrane to effect gas-liquid contact Org. Lett. 2010, 12, 1596-1598. (b) Polyzos, A.; O'Brien, M.; Petersen, T. P.; Baxendale, I. R.; Ley, S. V. The continuous-flow synthesis of carboxylic acids using $\mathrm{CO}_{2}$ in a tube-in-tube gas permeable membrane reactor Angew. Chem. Int. Ed. 2011, 50, 1190-1193. (c) Brzozowski, M.; O'Brien, M.; Ley, S. V.; Polyzos, A. Flow chemistry: intelligent processing of gas-liquid transformations using a tube-in-tube reactor. Acc. Chem. Res. 2015, 48, 349362.(d) Mallia, C. J.; Baxendale, I. R. The use of gases in flow synthesis. Org. Process Res. Dev. 2016, 20, 327-360.

(19) For selected applications of the tube-in-tube reactor in carbonylation reactions see (a) Gross, U.; Koos, P.; O'Brien, M.; Polyzos, A.; Ley, S. V. A general continuous flow method for palladium catalyzed carbonylation reactions using single and multiple tube-in-tube gas-liquid microreactors. Eur. J. Org. Chem. 2014, 2014, 6418-6430. (b) Koos, P.; Gross, U.; Polyzos, A.; O'Brien, M.; Baxendale, I.; Ley, S. V. Teflon AF-2400 mediated gas-liquid contact in continuous flow methoxycarbonylations and in-line FTIR measurement of CO 
concentration Org. Biomol. Chem. 2011, 9, 6903-6908. (c) Mallia, C. J.; Walter, G. C.; Baxendale, I. R. Flow carbonylation of sterically hindered ortho-substituted iodoarenes. Beilstein J. Org. Chem. 2016, 12, 1503-1511. (d) Brancour, C.; Fukuyama, T.; Mukai, Y.; Skrydstrup, T.; Ryu, I. Modernized low pressure carbonylation methods in batch and flow employing common acids as a CO source. Org. Lett. 2013, 15, 2794-2797.

(20) Ren, L.; Xinwei, L.; Jiao, N. Dioxygen-promoted Pd-catalyzed aminocarbonylation of organoboronic acids with amines and CO: a direct approach to tertiary amides. Org. Lett. 2016, 18, 5852-5855.

(21) (a) Perry, R. J.; Wilson, D. B. Palladium-catalyzed carbonylation and coupling reactions of aryl chlorides and amines. J. Org. Chem. 1996, 61, 7482-7485. (b) Lagueux-Tremblay, P.-L.; Fabrikant, A.; Arndsten, B. A. Palladium-catalyzed carbonylation of aryl chlorides to electrophilic aroyl-DMAP salts. ACS Catal. 2018, 8, 5350-5354. (c) Martinelli, J. R.; Clark, T. P.; Watson, D. A.; Munday, R. H.; Buchwald, S. L. Palladium-catalyzed aminocarbonylation of aryl chlorides at atmospheric pressure: the dual role of sodium phenoxide. Angew. Chem. Int. Ed. 2007, 46, 8460-8463.

(22) (a) Zhang, M.; Ruzi, R.; Xi, J.; Li, N.; Wu, Z.; Li, W.; Yu, S.; Zhu, C. Photoredox-catalyzed hydroacylation of olefins employing carboxylic acids and hydrosilanes Org. Lett. 2017, 19, 3430-3433. (b) Goti, G.; Bieszczad, B.; Vega-Peñaloza, A.; Melchiorre, P. Stereocontrolled synthesis of 1,4-dicarbonyl compounds by photochemical organocatalytic acyl radical addition to enals. Angew. Chem. Int. Ed. 2019, 58, 1213-1217. (c) Morack, T.; Mück Lichtenfeld, C.; Gilmour, R. Bioinspired Radical Stetter Reaction: Radical Umpolung Enabled by Ion-Pair Photocatalysis. Angew. Chem. Int. Ed. 2019, 58, 1208-1212.

(23) (a) Alvarado, J. I. M.; Ertel, A. B.; Stegner, A.; Stache, E. E.; Doyle, A. G. Direct use of carboxylic acids in the photocatalytic hydroacylation of styrenes to generate dialkyl ketones Org. Lett. 2019, 21, 9940-9944. (b) Fan, X.; Lei, T.; Chen, B.; Tung, C.-H.; Wu, L.-Z. Photocatalytic C-C Bond Activation of Oxime Ester for Acyl Radical Generation and Application Org. Lett. 2019, 21, $4153-4158$. (c) Ryu, I.; Tani, A.; Fukuyama, T.; Ravelli, D.; Fagnoni, M.; Albini, A. Atom-economical synthesis of unsymmetrical ketones through photocatalyzed c-h activation of alkanes and coupling with co and electrophilic alkenes. Angew. Chem. Int. Ed. 2011, 50, $1869-1872$. (d) Cartier, A.; Levernier, E.; Corcé, V.; Fukuyama, T.; Dhimane, A. L.; Ollivier, C.; Ryu, I.; Fensterbank, L. Carbonylation of alkyl radicals derived from organosilicates through visible-light photoredox catalysis. Angew. Chem. 2019, 131, 1803-1807.

(24) Uozumi, Y.; Arii, T.; Watanabe, T. Double carbonylation of aryl iodides with primary amines under atmospheric pressure conditions using the $\mathrm{Pd} / \mathrm{PPh}_{3} / \mathrm{DABCO} / \mathrm{THF}$ system. J. Org. Chem. 2001, 66, 5272-5274.

(25) Andrieux, C. P.; Gallardo, I.; Savéant, J.-M.; Su, K.-B. Dissociative electron transfer. Homogeneous and heterogeneous reductive cleavage of the carbon-halogen bond in simple aliphatic halides J. Am. Chem. Soc. 1986, 108, 638-647.

(26) (a) Corbet, M.; De Campo, F. 8-Aminoquinoline: A powerful directing group in metal-catalyzed direct functionalization of C-H bonds. Angew. Chem. Int. Ed. 2013, 52, 9896-9898. (b) Sambiagio, C.; Schönbauer, D.; Blieck, R.; Dao-Huy, T.; Pototschnig, G.; Schaaf, P.; Wiesinger, T.; Zia, M. F.; Wencel-Delord, J.; Besset, T.; Maes, B. U. W.; Schnürch, M. A comprehensive overview of directing groups applied in metal-catalyzed C-H functionalization chemistry. Chem. Soc. Rev. 2018, 47, 6603-6743. (c) Shabashov, D.; Daugulis, O. Auxiliary-assisted palladium-catalyzed arylation and alkylation of $\mathrm{sp}^{2}$ and $\mathrm{sp}^{3}$ carbon-hydrogen bonds. J. Am. Chem. Soc. 2010, 132, 3965-3972.

(27) (a) Devery, J. J., III; Nguyen, J. D.; Dai, C.; Stephenson, C. R. J. Light-mediated reductive debromination of unactivated alkyl and aryl bromides. ACS Catal. 2016, 6, 5962-5967. (b) Shen, Y.; Cornella, J.; Juliá-Hernández, F.; Martin, R. Visible-light-promoted atom transfer radical cyclization of unactivated alkyl iodides. ACS Catal. 2017, 7, 409-412. (c) Bissonnette, N. B.; Boyd, M. J.; May, G. D.; Simon, G.; Philippe, N. C-H functionalization of heteroarenes using unactivated alkyl halides through visible-light photoredox catalysis under basic conditions. J. Org. Chem. 2018, 83, 10933-10940. (d) Alpers, D.; Cole, K. P.; Stephenson, C. R. J. Visible light mediated aryl migration by homolytic c-n cleavage of aryl amines. Angew. Chem. Int. Ed. 2018, 57, 12167-12170.

(28) (a) Matsubara, H.; Ryu, I.; Schiesser, C. H. An ab initio and DFT study of some halogen atom transfer reactions from alkyl groups to acyl radical. Org. Biomol Chem. 2007, 5, 3320-3324. (b) Nagahara, K.; Ryu, I.; Komatsu, M.; Sonoda, N. Radical carboxylation: ester synthesis from alkyl iodides, carbon monoxide, and alcohols under irradiation conditions. J. Am. Chem. Soc. 1997, 119, 54655466.

(29) Kawamoto, T.; Sato, A.; Ryu, I. Photoinduced aminocarbonylation of aryl iodides Chem. Eur. J. 2015, 21, $14764-14767$.

(30) Kawamoto, T.; Matsubara, H.; Fukuyama, T.; Ryu, I. A theoretical study on radical-based aminocarbonylation of aryl iodides. Chem. Lett. 2018, 47, 1169-1171. 